\title{
Memo interacts with c-Src to control Estrogen Receptor alpha sub-cellular localization
}

\author{
Anna Frei ${ }^{1,4}$, Gwen MacDonald ${ }^{1}$, Ingrid Lund ${ }^{2}$, Jan-Åke Gustafsson ${ }^{2,3}$, Nancy E. \\ Hynes $^{1,4}$ and Ivan Nalvarte ${ }^{2}$ \\ ${ }^{1}$ Friedrich Miescher Institute for Biomedical Research, Maulbeerstrasse, Basel, Switzerland \\ 2 Department of Biosciences and Nutrition, Karolinska Institutet, Huddinge, Sweden \\ ${ }^{3}$ Center for Nuclear Receptors and Cell Signaling, Department of Biology and Biochemistry, University of Houston, Houston, \\ TX, USA \\ ${ }^{4}$ University of Basel, Basel, Switzerland \\ Correspondence to: Ivan Nalvarte, email: ivan.nalvarte@ki.se
}

Keywords: Memol, heregulin, ER alpha, estrogen, c-Src

Received: June 30, $2016 \quad$ Accepted: July 14, 2016

Published: July 26, 2016

\section{ABSTRACT}

Understanding the complex interaction between growth factor and steroid hormone signaling pathways in breast cancer is key to identifying suitable therapeutic strategies to avoid progression and therapy resistance. The interaction between these two pathways is of paramount importance for the development of endocrine resistance. Nevertheless, the molecular mechanisms behind their crosstalk are still largely obscure. We previously reported that Memo is a small redox-active protein that controls heregulin-mediated migration of breast cancer cells. Here we report that Memo sits at the intersection between heregulin and estrogen signaling, and that Memo controls Estrogen Receptor alpha (ERa) sub-cellular localization, phosphorylation, and function downstream of heregulin and estrogen in breast cancer cells. Memo facilitates ERa and C-Src interaction, ERa Y537 phosphorylation, and has the ability to control ERa extra-nuclear localization. Thus, we identify Memo as an important key mediator between the heregulin and estrogen signaling pathways, which affects both breast cancer cell migration and proliferation.

\section{INTRODUCTION}

Estrogen (E2) binds and activates estrogen receptors (ERs) to enter the nucleus and regulate the expression of genes involved in cell survival, proliferation and differentiation [1]. In hormone responsive breast cancer, ER alpha $(\mathrm{ER} \alpha)$ is an important driver of proliferation, and is a first-line target for therapy. However, ER $\alpha$ positive breast cancers often acquire endocrine resistance and escape such therapy, likely through the activation of alternative mitotic pathways or ligand independent activation of ER $\alpha$ [2]. Phosphorylation of ER $\alpha$ can regulate both its ligand-dependent and -independent transcriptional activity. The phosphorylation of $\operatorname{ER} \alpha$ at tyrosine 537 (Y537) is mediated by the c-Src (Src) kinase and promotes ER $\alpha$ hormone-binding, dimerization, and activity [3-6]. However, this phosphorylation is also known to increase ER $\alpha$ association with Src to promote Src activation, as well as ER $\alpha$ extra-nuclear localization $[5,7,8]$.

Mediator of ErbB2-driven cell motility, Memo (gene name $M E M O 1$ ), is a small ubiquitous redox-active protein with an important role in breast cancer cell migration, invasion, and metastasis downstream of growth factor signaling $[9,10]$. Memo is located both in the nucleus and cytoplasm $[11,12]$, and its expression has been found to be increased in $>40 \%$ of primary breast tumors, where its cytoplasmic localization correlated with aggressive disease parameters, such as Luminal B subtype, earlydistant recurrence, and death [9]. Apart from conveying migratory signals from receptor tyrosine kinases (RTKs) such as the human epidermal growth factor receptor 2 (HER2), Memo was recently shown to interact with ER $\alpha$ and $\operatorname{ER} \beta$ and to promote ER $\alpha$ phosphorylation and ligand- 
independent activation [13]. These data suggest that in addition to RTK signaling Memo may have an important role in estrogen signaling. However, how Memo might function to integrate these two mitogenic pathways has not been explored. Memo is known to have a role in heregulin- (HRG) mediated migration $[9,10]$ in breast cancer cells. Here, we provide mechanistic insight into how Memo controls ER $\alpha$ function and E2-mediated cell migration. We show that Memo regulates ER $\alpha$ function through controlling its extra-nuclear localization. This is especially striking upon simultaneous activation of the HRG and E2 pathways. Further, Memo promotes the interaction between $\mathrm{ER} \alpha$ and Src in the cytoplasm and increases Src Y418 and ER $\alpha$ Y537 phosphorylation with consequences for proliferation and migration, as well as endocrine treatment response. Based on these results, we propose that Memo resides at the intersection between HRG and E2 signaling in breast cancer, and is an important new player in the crosstalk between the two pathways.

\section{RESULTS}

\section{Memo controls HRG-mediated expression of ERa target genes}

To analyze the function of Memo on ER $\alpha$ downstream of E2 and HRG we chose the ER $\alpha+$ / HER2+ (non-overexpressing, luminal B-like) human breast cancer cell line T47D stably expressing a control, non-targeting (NT), short hairpin RNA (shRNA), or one expressing Memo shRNA (Sh5) (Figure 1A). When analyzing the $\mathrm{ER} \alpha$ transcriptional activity in these cells by using a $3 \mathrm{x}$ ERE luciferase reporter construct, there was no difference in E2 mediated ER $\alpha$ activity upon Memo knockdown (Sh5) (Figure 1B). As described before [14], treating the cells with HRG significantly increased ER $\alpha$ activity, however, only in control NT cells. Surprisingly, combined E2 and HRG treatment decreased ER $\alpha$ 's activity compared to E2 treatment for NT cells, and to a lesser extent for Sh5 cells (Figure 1B). This was also reflected in the expression of the classical ER $\alpha$ target genes GREB1 (Figure 1C), PS2 (Figure 1D) and Cyclin D1 (Figure 1E). We did not see any decrease in their E2-mediated expression upon Memo knockdown. In contrast, we found a slight, and sometimes significant, increase in their basal (E2-independent, Figure 1C, 1D) and E2-mediated (Figure 1D) expression in Sh5 cells. Interestingly, combined HRG and E2 treatment generally increased expression more in Sh5 cells compared to NT cells. Although E2 treatment only gave a $\sim 2.5$ fold increase in Cyclin D1 expression (Figure 1E), we could detect a significant enrichment of $\operatorname{ER} \alpha$ at the estrogen response element (ERE) promoter site of this gene (Figure 1F). The HRG treatment also increased ER $\alpha$ enrichment in NT but not in Sh5 cells. In contrast, combined HRG and E2 treatment increased ER $\alpha$ binding only in Sh5 cells (Figure 1F). This implies that ER $\alpha$ can increase cyclin D1 mRNA expression by its enrichment at the promoter of cyclin D1 upon HRG and E2 stimulation. These data also suggest that Memo promotes HRG-mediated ER $\alpha$ activation and promotes antagonizing effects of HRG on E2-induced ER $\alpha$ activity.

\section{Memo regulates ERa nuclear localization downstream of HRG}

Lower nuclear levels or lower general levels of ER $\alpha$ could account for the observed differences in $\mathrm{ER} \alpha$ target gene expression between NT and Sh5 cells. However, there were no apparent differences in ER $\alpha$ mRNA or protein levels between NT and Sh5 cells (Supplementary Figures $1 \mathrm{~A}$ and 2). In contrast, we saw a striking difference in ER $\alpha$ nuclear localization upon HRG and combined HRG and E2 treatment. HRG treatment caused an increased ER $\alpha$ nuclear localization in NT cells already following $10 \mathrm{~min}$ HRG treatment, which was absent in Sh5 cells (Figure $1 \mathrm{G}$ and H; Supplementary Figure 1B). Combined HRG and E2 treatment almost totally abolished ER $\alpha$ nuclear localization in NT cells, while its localization in Sh5 cells was not affected (Figure $1 \mathrm{G}$ and 1H; Supplementary Figure 1B). After $45 \mathrm{~min}$ of treatment ER $\alpha$ relocalized to its original localizations in both NT and Sh5 cells (Supplementary Figure 1B). Furthermore, Memo localized to the nucleus upon HRG or E2 treatment (Figure $1 \mathrm{G}$ and 1I; Supplementary Figure 1C). We also observed similar effects after stimulation with $10 \mathrm{~min} H R G$ and E2 on the nuclear localizations of ER $\alpha$ and Memo in parental MCF7 cells (Supplementary figure 2A, B), suggesting that our observations could be a general phenomenon for HRGresponding ER $\alpha$-positive breast cancer cells. Further, HRG treatment also promoted Memo to localize to membrane ruffles in T47D cells [11, 15] and co-localized with ER $\alpha$ at these sites (Supplementary Figure 1D).

\section{Memo promotes ER $\alpha$ and c-Src phosphorylation}

Previous reports $[5,7,8]$ have described the Srcdependent phosphorylation of ER $\alpha$ at Y537 (PY537$\operatorname{ER} \alpha$ ) as being required for its extra-nuclear localization. Interestingly, we could already observe a strong increase in PY537 and PS118-ER $\alpha$ levels after 5-10 min of combined HRG and E2 treatment (Figure 2A-2C; Supplementary Figure $3 \mathrm{~A}-3 \mathrm{~B})$. This increase was significantly lower in Sh5 cells. No clear difference was observed for PS167ER $\alpha$ (Figure 2A). In addition, PY418-Src was significantly increased in NT cells compared to Sh5 cells, however, only upon combined HRG and E2 treatment (Figure 2D, 2E). We could not observe any significant difference in Y1248HER2, S473-Akt, and T202/Y204-Erk1/2 phosphorylation 


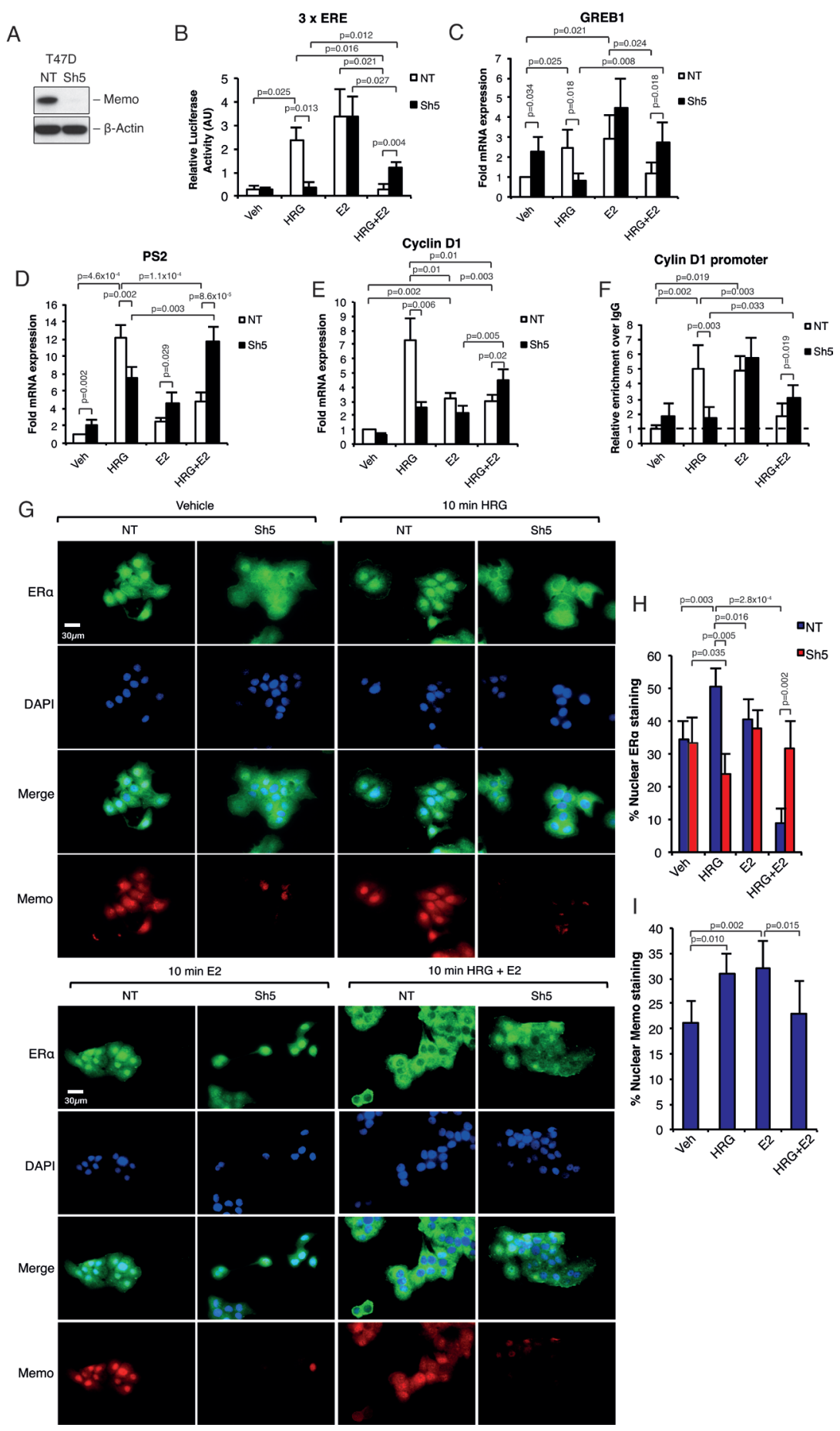

Figure 1: Memo controls HRG-mediated ER $\alpha$ target gene expression and ER $\alpha$ extra-nuclear localization. A. Western blot analysis of Memo protein levels in T47D NT control and Sh5 Memo KD cells. B. ER $\alpha$ activity upon E2 and or HRG stimulation for 48h. Firefly luciferase activity was normalized to renilla luciferase activity $(\mathrm{n}=3)$. C. Relative mRNA expression of GREB1 in T47D cells cultured in the presence of DMSO (Vehicle, Veh), HRG, E2 and HRG+E2 for $24 \mathrm{~h}(\mathrm{n}=5)$. D. Relative mRNA expression of PS2 in T47D cells cultured as in (B) $(\mathrm{n}=5)$. E. Relative mRNA expression of Cyclin D1 in T47D cells cultured as in (B) but for $6 \mathrm{~h}(\mathrm{n}=3)$. F. ChIP analysis showing the recruitment of ER $\alpha$ to the ERE promoter sequence of Cyclin D1 in T47D NT and Sh5 cells treated with DMSO, HRG, and/or E2 for $30 \mathrm{~min}(\mathrm{n}=3)$. Dotted line indicates enrichment level with non-specific IgG. G. Immunofluorescence (IF) analysis showing the cytoplasmic/nuclear localization of ER $\alpha$ and Memo in NT and Sh5 T47D cells treated with DMSO (vehicle), HRG and/or E2 for 10 minutes. Nuclei were stained with DAPI. 40x magnification, Scale bar: $30 \mu \mathrm{M}$. H. Quantification of nuclear ER $\alpha$ IF intensity as percentage of total ER $\alpha$ IF intensity $(n=7)$. I. Quantification of nuclear Memo IF intensity as percentage of total Memo IF intensity $(n=5)$. The data shown in (B-F) and (H-I) represent means and error bars represent standard deviation (S.D.), $P$ values were determined using Student's t-test or one-way ANOVA. 

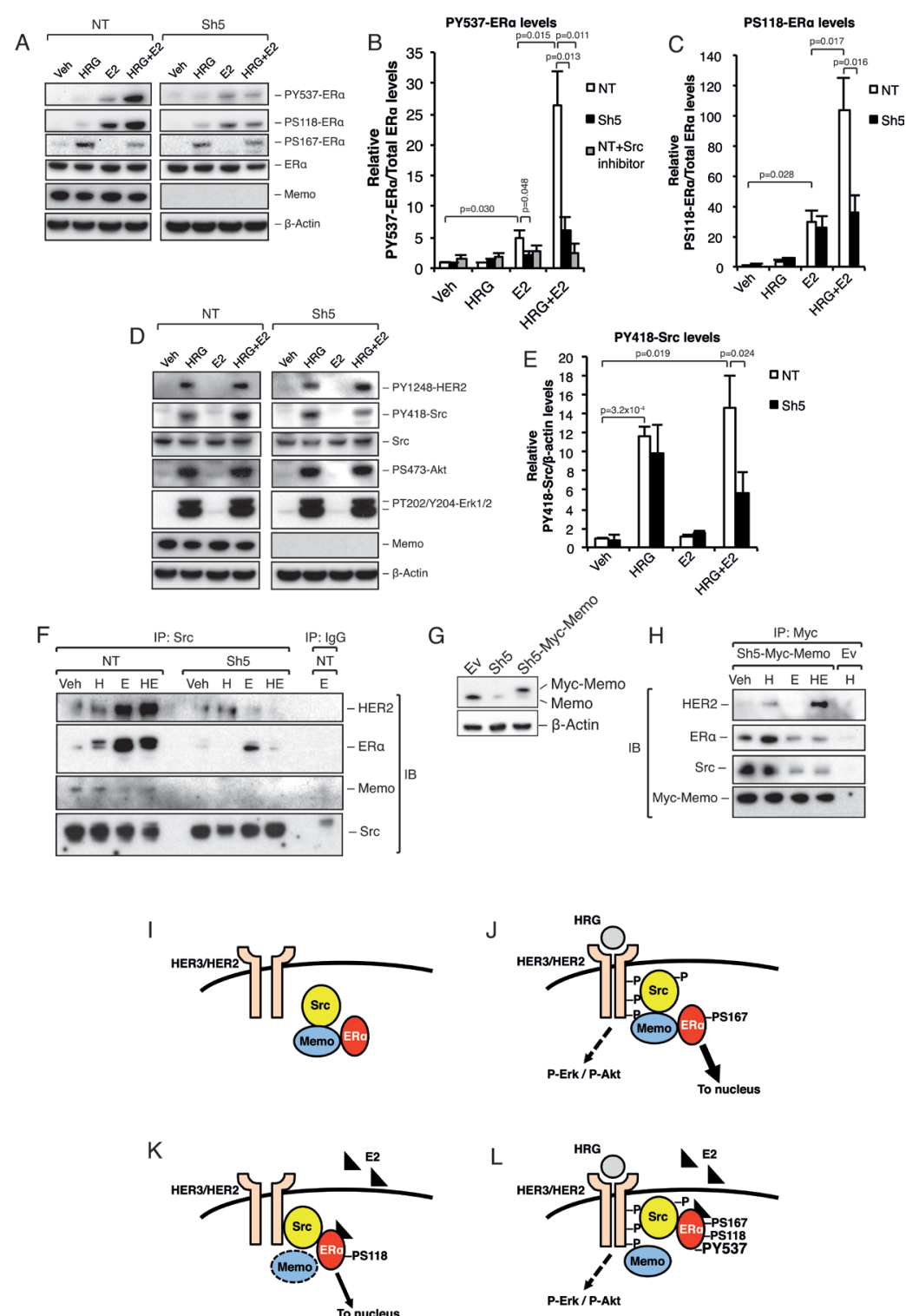

Figure 2: Memo promotes ERa phosphorylation and interaction with Src upon HRG and E2 treatment. A. Western blot analysis of ER $\alpha$ phosphorylation status in T47D NT and Sh5 cells treated with DMSO (Veh), HRG, and/or E2 for 10 min. B. Quantification of relative PY537-ER $\alpha$ levels $(\mathrm{n}=3)$ in the presence or absence of $500 \mathrm{nM}$ Src inhibitor-1. C. Quantification of relative PS118-ER $\alpha$ levels $(\mathrm{n}=3)$. D. Western blot analysis of HER2, Src, Akt, and Erk1/2 phosphorylation status in T47D NT and Sh5 cells treated with DMSO, HRG, and/or E2 for 10 min. E. Quantification of relative PY418-Src levels ( $n=3)$. F. Immunoprecipitation (IP) of Src in NT and Sh5 T47D cells treated for 10 min with DMSO (Veh), HRG (H) and/or E2 (E), followed by immunoblotting (IB) for HER2, ER $\alpha$, Memo and Src. G. Memo and Myc-Memo protein levels in T47D cells transfected with an empty pLHCX vector (Ev), Sh5 KD construct, and Sh5 cells transfected with pLHCX-Myc-Memo (Sh5-Myc-Memo). H. IP of Myc-Memo in T47D Sh5-Myc-Memo cells treated for 10 min with DMSO (Veh), HRG and/or E2, followed by immunoblotting (IB) for HER2, ER $\alpha$, Src, and Memo. T47D Ev cells were used as a control. I. Proposed model for Src, Memo and ER $\alpha$ interaction (I-L). Under basal conditions, without HRG or E2 stimulation, Memo associates with both Src and ER $\alpha$. However, Src and ER $\alpha$ do not appear to bind each other directly. J. HRG treatment induces HER2 heterodimerization and phosphorylation as well as recruitment of the Memo-Src-ER $\alpha$ complex to HER2. The HER2 activation promotes phosphorylation and activation of Src as well as Erk1/2 and Akt pathways. This in turn promotes ligand independent activation, likely through its phosphorylation at S167, and a strong Memo-dependent ER $\alpha$ nuclear translocation. K. Upon E2 treatment ER $\alpha$ changes conformation that likely disrupts the ER $\alpha$-Memo interaction. However, the ER $\alpha$ interaction with the Src-HER2 complex is still Memo dependent. E2 promotes ER $\alpha$ S118 and Y537 phosphorylation, resulting in ER $\alpha$ activation and nuclear translocation. L. Upon combined HRG and E2 treatment, Memo binds to HER2, and the E2 binding to ER $\alpha$ prevents Memo's complex formation with ER $\alpha$. Nevertheless, Memo is required for this Src-ER $\alpha$ interaction. The HRG activation of HER2 and Src increases the binding of ER $\alpha$ to Src. This in turn increases the phosphorylation of ER $\alpha$ on S118 and especially Y537, resulting in a very tight Src-ER $\alpha$ complex and preventing ER $\alpha$ from entering the nucleus. The data shown in (B, C, E) represent means and error bars represent standard deviation (S.D.). The IPs (F) and (H) are representative of 3 independent experiments. $P$ values were determined using Student's t-test or one-way ANOVA. 
between the NT and Sh5 cells (Figure 2D). In order to test the dependence of ER $\alpha$-Y537 phosphorylation on active Src we used a Src inhibitor. Src inhibition significantly lowered ER $\alpha-Y 537$ phosphorylation to levels comparable to those in Sh5 cells (Figure 2B, gray bars, Supplemental Figure 3C). Our data suggest that the difference in ER $\alpha$ sub-cellular localization between NT and Sh5 cells stimulated with HRG and E2 may be due to differences in PY537-ER $\alpha$ levels mediated to a significant extent by Src and Memo.

\section{Memo interacts with Src and promotes its interaction with $\mathbf{E R \alpha}$}

$\mathrm{ER} \alpha$ phosphorylation at $\mathrm{Y} 537$ is known to promote a tight extra-nuclear interaction with Src, which increases PY418-Src levels and Src activation [5, 7, 8]. We hypothesized that such an interaction could underlie ER $\alpha$ extra-nuclear localization upon combined HRG and
E2 treatment. Interestingly, immunoprecipitation (IP) of cytoplasmic Src revealed enriched binding to ER $\alpha$ upon E2 and combined E2-HRG treatment (Figure 2F). This interaction was greatly reduced in Sh5 cells. In addition, HER2 also interacted with Src upon E2 and combined E2HRG treatment. Interestingly, the opposite was seen for Memo that interacted more with Src upon basal conditions or upon treatment with only HRG (Figure 2F).

To further study the interaction between Memo and the Src-ER $\alpha$ complex we used T47D Sh5 cells stably expressing a Myc-tagged Memo rescue vector (Figure 2G). We observed that Myc-tagged Memo interacted with Src and ER $\alpha$ under basal conditions and upon HRG treatment (Figure 2H). Treatments with E2 decreased this interaction. Memo also interacted with HER2, however, only upon HRG and combined HRG-E2 treatment (Figure $2 \mathrm{H}$ ). These data are summarized in Figure 2I-2L, and suggest that Memo is necessary for the interaction between $\mathrm{ER} \alpha$, Src, and HER2. These data also demonstrate that this interaction is not necessarily dependent on an active Src.
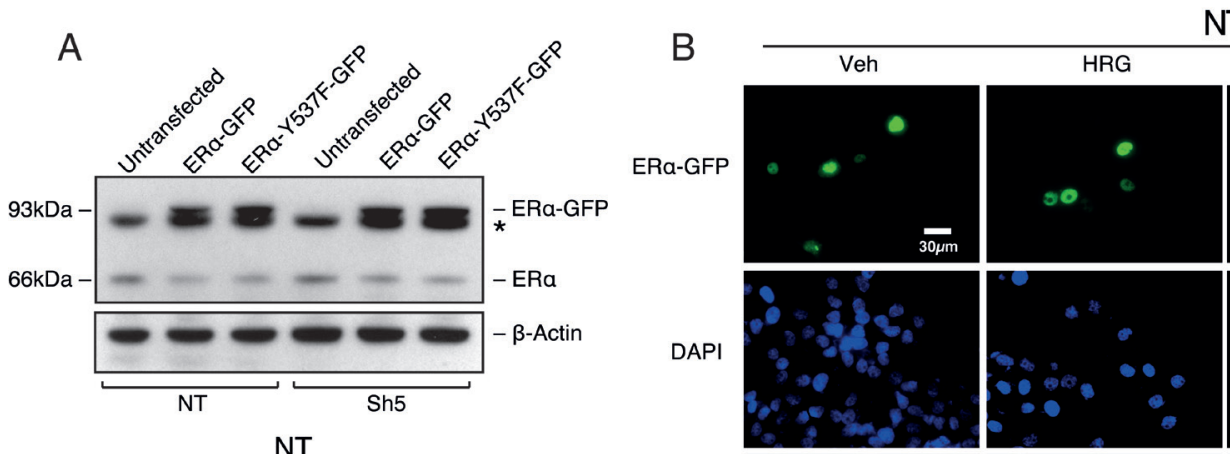

NT
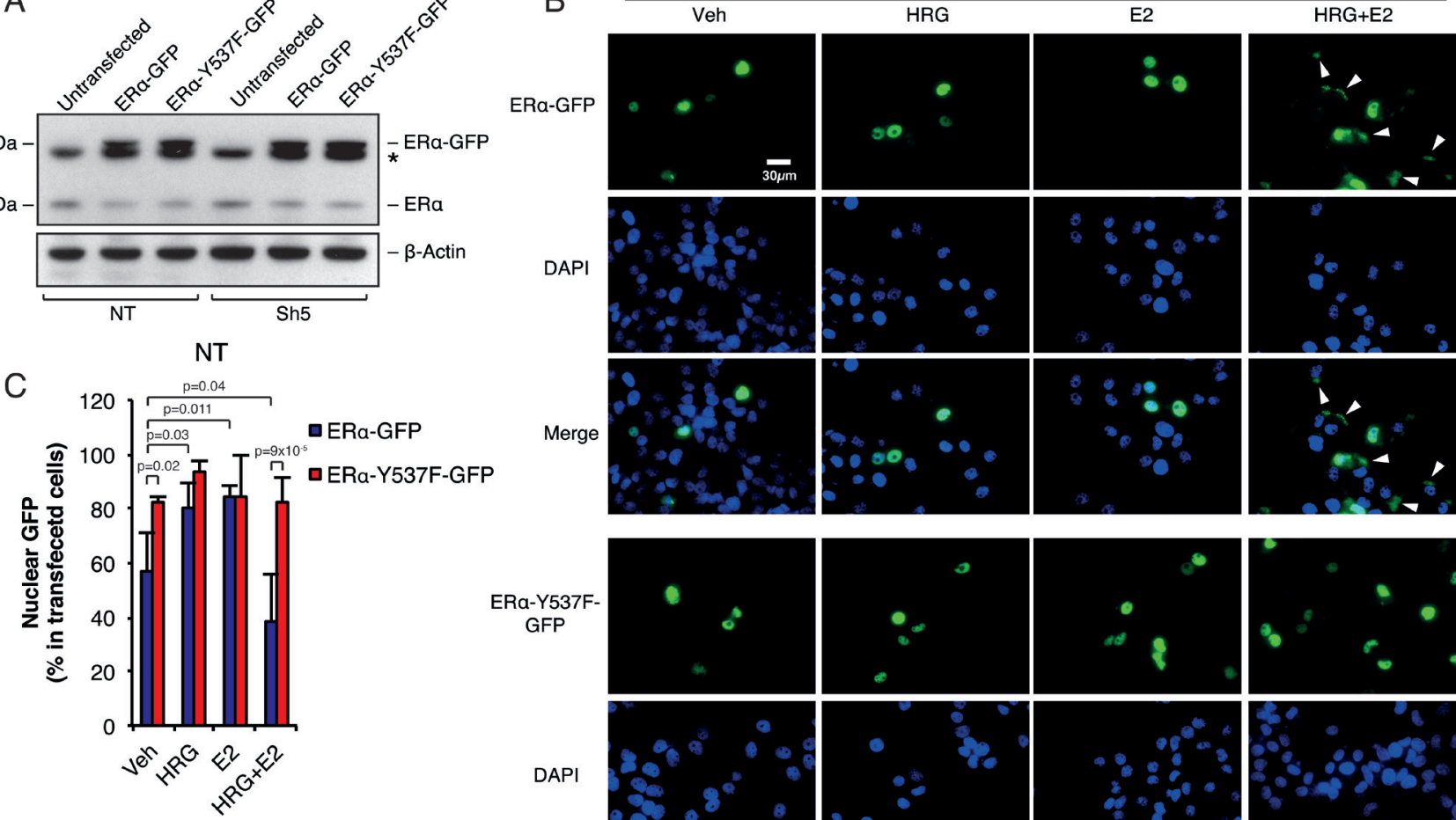

DAPI
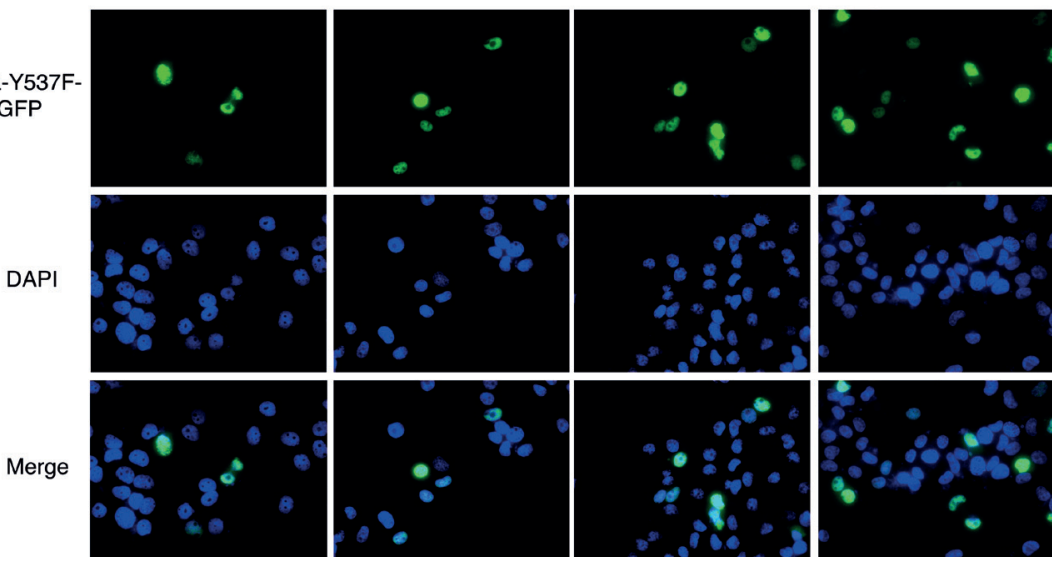

Figure 3: Memo controls ER $\alpha$ extra-nuclear localization through ER $\alpha$-Y537 phosphorylation. A. Western blot analysis of endogenous ER $\alpha$ and GFP-tagged WT or Y537F ER $\alpha$. Asterisk indicates an unspecific band. B. Immunofluorescence (IF) analysis showing the cytoplasmic/nuclear localization of ER $\alpha$-WT-GFP and ER $\alpha$-Y537F-GFP in NT T47D cells treated with DMSO (vehicle), HRG and/or E2 for 10 minutes. Nuclei were stained with DAPI. 40x magnification, Scale bar: $30 \mu \mathrm{M}$. C. Quantification of nuclear ER $\alpha$-GFP IF intensity as percentage of total ER $\alpha$ IF intensity $(\mathrm{n}=6)$. The data shown in $(\mathrm{C})$ represent means and error bars represent standard deviation (S.D.), $P$ values were determined using one-way ANOVA. 

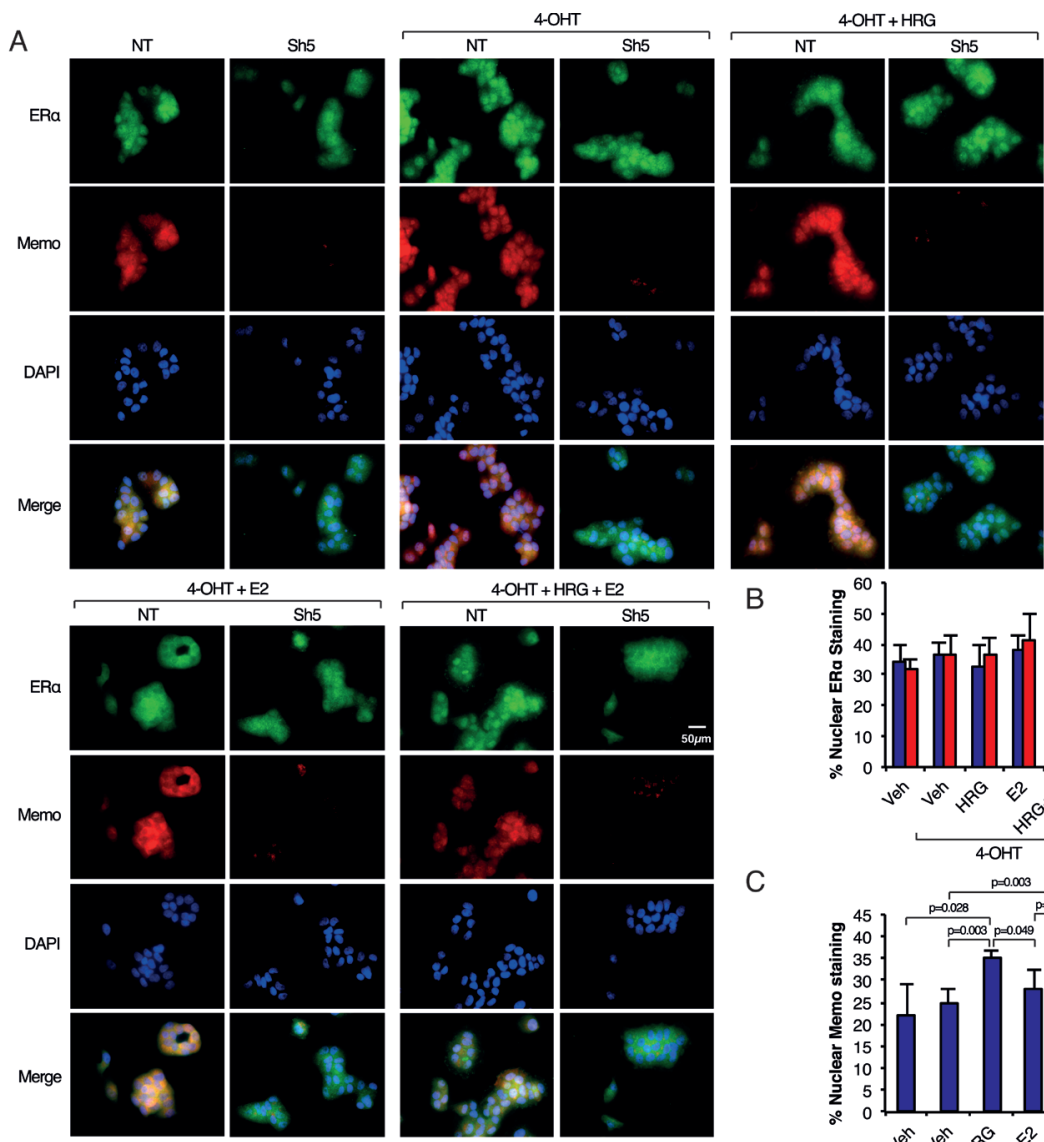

B

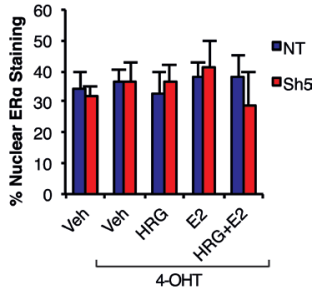

C
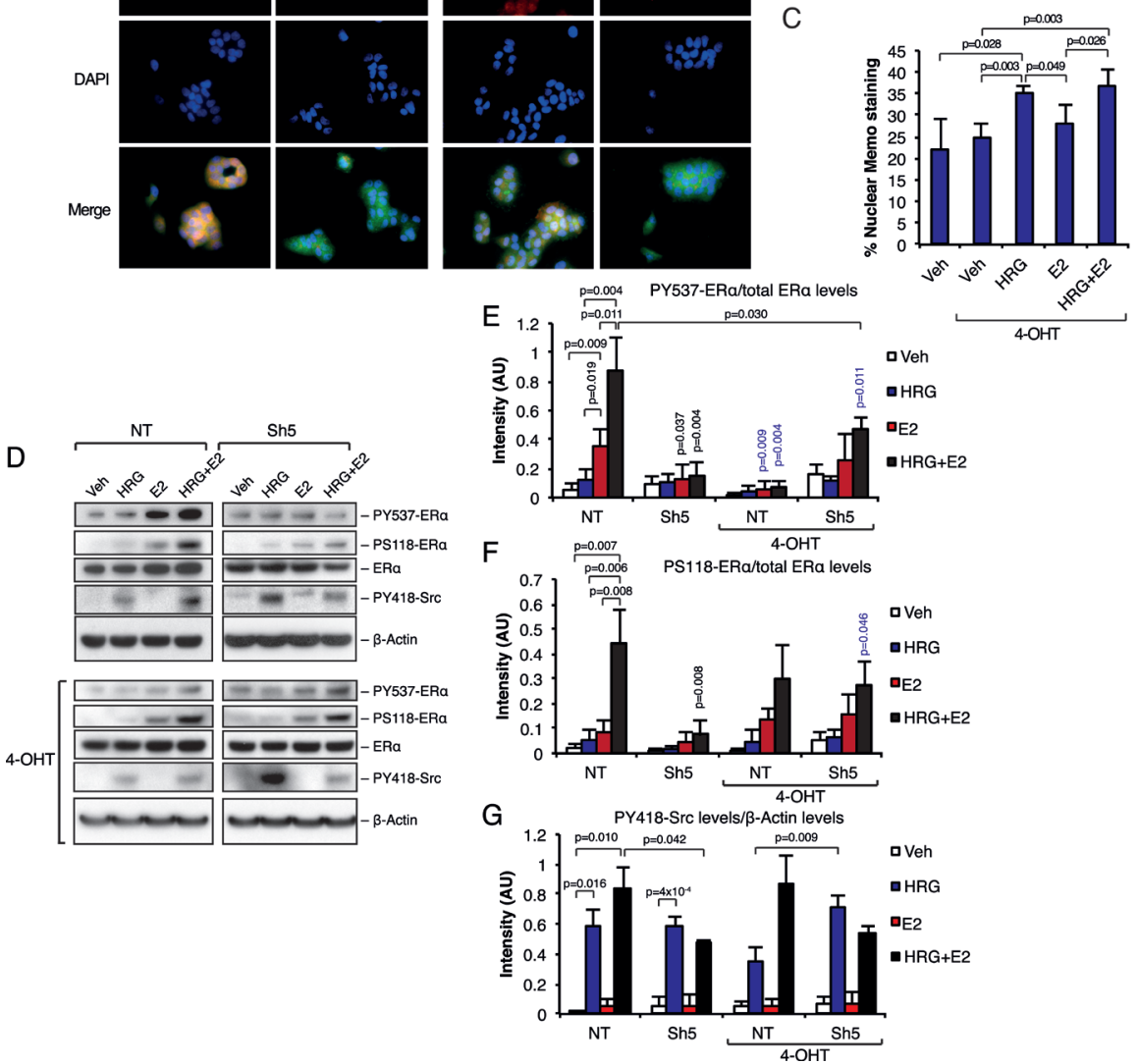

Figure 4: Inhibition of ERa abolishes the effects of Memo on ER $\boldsymbol{\alpha}$. A. Immunofluorescence (IF) analysis showing the cytoplasmic/nuclear localization of ER $\alpha$ and Memo in NT and Sh5 T47D cells treated with 4-OHT, HRG and E2 for 10 minutes. Nuclei were stained with DAPI. 40x magnification, Scale bar: $50 \mu \mathrm{M}$. B. Quantification of nuclear ER $\alpha$ IF intensity as percentage of total ER $\alpha$ IF intensity $(\mathrm{n}=4)$. C. Quantification of nuclear Memo IF intensity as percentage of total Memo IF intensity $(\mathrm{n}=4)$. D. Western blot analysis of PY537-ER $\alpha$, PS118-ER $\alpha$, and PY418-Src levels in starved T47D cells treated with $2 \mathrm{nM} \mathrm{HRG,} 10 \mathrm{nM}$ E2, DMSO (Veh), and/or 20 nM 4-OHT for $10 \mathrm{~min}$. E. Quantification of PY537-ER $\alpha$ levels relative to total ER $\alpha$ levels (AU, arbitrary units) $(\mathrm{n}=3)$. F. Quantification of PS118-ER $\alpha$ levels relative to total ER $\alpha$ levels (AU, arbitrary units) $(n=3)$. G. Quantification of PY418-Src levels relative to $\beta$-Actin levels (AU, arbitrary units) $(\mathrm{n}=3)$. The data shown in $(\mathrm{B}, \mathrm{C}, \mathrm{E}-\mathrm{F})$ represent means and error bars represent S.D. Significance levels written in blue show the significance between 4-OHT treatment and the respective treatment without 4-OHT. $P$ values were determined using Student's t-test or one-way ANOVA. 


\section{ERa Y537F mutant inhibits ER $\alpha$ extra-nuclear localization similar to Memo knockdown}

In order to confirm that Memo mediates its effect on ER $\alpha$ extra-nuclear localization through the ER $\alpha$-Y537 phosphorylation site, we generated an ER $\alpha$-Y537F mutant. It has previously been shown that the ER $\alpha$-Y 537 site is needed for ER $\alpha$ nuclear export [7]. Overexpression of ER $\alpha$-WT-GFP and ER $\alpha$-Y537F-GFP constructs in T47D NT and Sh 5 cells (Figure 3A) resulted in generally higher nuclear ER $\alpha$-WT-GFP levels under basal conditions $(\sim 55 \%$ nuclear GFP) (Figure 3B, 3C, and Supplementary Figure 4A, B) compared with endogenous ER $\alpha(\sim 35 \%)$ (Figure 1G, 1H). Treatment of NT cells with HRG or

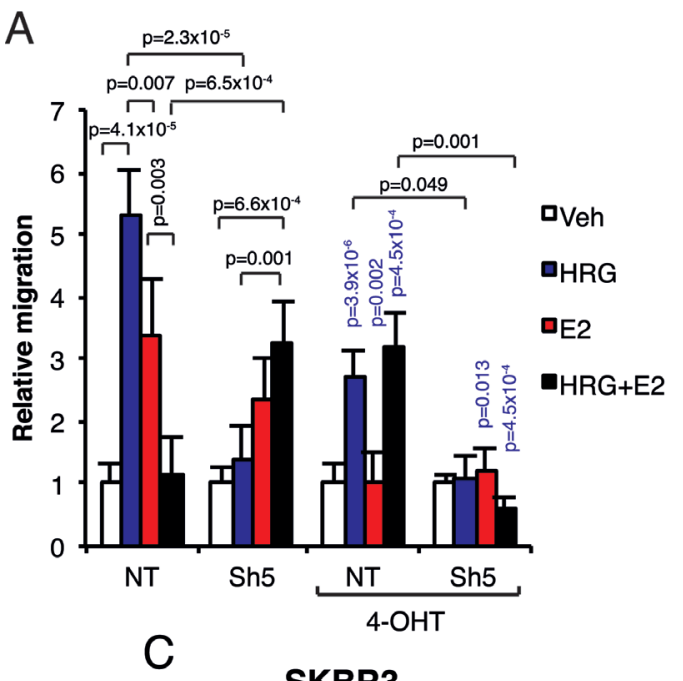

E2 resulted further increased ER $\alpha$-WT-GFP nuclear localization $(\sim 80 \%)$. However, similar to endogenous $\mathrm{ER} \alpha$, combined HRG and E2 treatment greatly reduced the nuclear ER $\alpha$-WT-GFP levels (to $\sim 40 \%$ ) (Figure 3B, 3C). The ER $\alpha-Y 537 F-G F P$ mutant overexpressing cells had high basal nuclear ER $\alpha$ levels and these levels did not change with any treatment combination (Figure 3B, 3C). In contrast to NT cells, overexpression of ER $\alpha$ WT-GFP in Sh5 cells did not result in increased nuclear localization upon HRG treatment, and no decreased nuclear localization could be observed upon combined HRG+E2 treatment (Supplementary Figure 4A-C). These data suggest the Memo can control ER $\alpha$ extra-nuclear localization via $\mathrm{ER} \alpha-\mathrm{Y} 537$ phosphorylation downstream of HRG and E2.

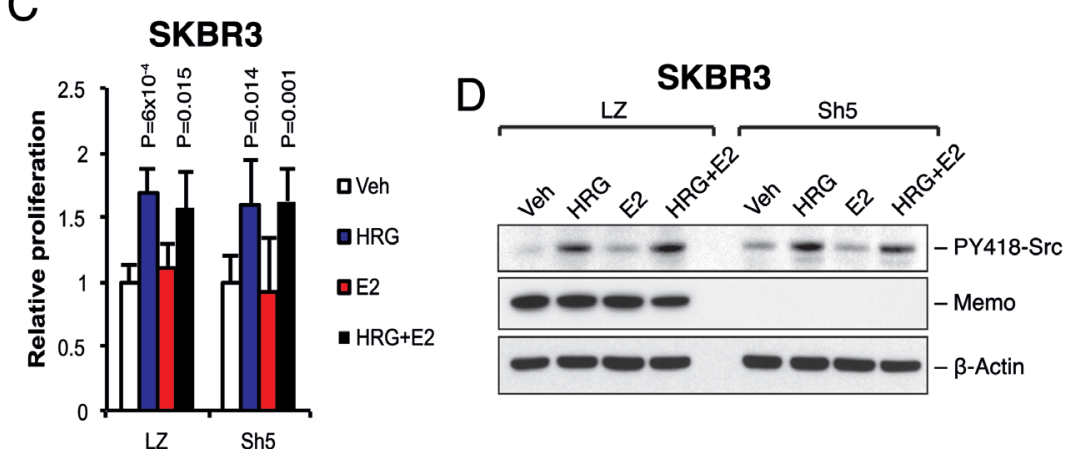

Figure 5: Memo together with ERa regulates cell migration and proliferation downstream of HRG and E2. A. Migration assay. Starved T47D cells were seeded into the upper transwell chamber. The lower wells contained phenol-free DMEM supplemented with 0.5\% DCC-treated FCS and $2 \mathrm{nM} \mathrm{HRG,} 10 \mathrm{nM} \mathrm{E2,} \mathrm{DMSO} \mathrm{(Veh),} \mathrm{and/or} 20 \mathrm{nM}$ 4-OHT. After 24 h the migrated cells were fixed, stained and counted. The migration is expressed relative to respective DMSO treated cells $(n=5)$. B. Proliferation assay. T47D cells were starved for 5 days in phenol-free DMEM supplemented with 0.5\% DCC-treated FCS, and in the presence of $2 \mathrm{nM} \mathrm{HRG,} 10 \mathrm{nM} \mathrm{E2,} \mathrm{DMSO} \mathrm{(Veh),}$ and/or $20 \mathrm{nM}$ 4-OHT. Viable cells were counted and the proliferation change was assessed relative to respective DMSO treated cells (n = 5). C. Proliferation of LZ (control) and Sh5 (Memo KD) SKBR3 cells was assessed as in (B) in the presence of $2 \mathrm{nM} \mathrm{HRG,} 10 \mathrm{nM} \mathrm{E2}$, and/or DMSO (Veh). Viable cells were counted and the proliferation change was assessed relative to respective DMSO treated cells $(\mathrm{n}=5)$. D. Western blot analysis of PY418-Src levels in LZ and Sh5 SKBR3 cells treated with $2 \mathrm{nM} \mathrm{HRG,} 10 \mathrm{nM} \mathrm{E2,} \mathrm{and/or} \mathrm{DMSO} \mathrm{(Veh)} \mathrm{for} \mathrm{10}$ min. The data shown in (A - C) represent means and error bars represent S.E.M. The data shown in (D) is representative of 3 independent experiments $(n=3)$. Significance levels written in blue show the significance between 4-OHT treatment and the respective treatment without 4-OHT. $P$ values were determined using Student's t-test or one-way ANOVA. 


\section{The effects of Memo on ER $\alpha$ requires a functional ERo}

We next investigated if the Memo-mediated subcellular localization and phosphorylation of ER $\alpha$ can be blocked by the ER $\alpha$ antagonist 4-hydroxy tamoxifen (4-OHT). We could not observe any difference in ERa sub-cellular localization when the cells were treated with 4-OHT in combination with HRG and/or E2 (Figure 4A and $4 \mathrm{~B}$ ), which was in contrast to the effects seen in Figure 1 (Figure $1 \mathrm{G}$ and $1 \mathrm{H}$ ). On the other hand, Memo localized to the nucleus upon the HRG treatments in the presence of 4-OHT (Figure 4A and 4C). Furthermore, 4-OHT abolished the PY537-ER $\alpha$ in T47D NT cells in response to E2 and HRG+E2 (Figure 4D and 4E). Surprisingly, 4-OHT treatment slightly, but significantly increased PY537-ER $\alpha$ in Sh5 cells in response to combined HRG and E2 stimulation. On the other hand, there was no difference in PS118-ER $\alpha$ between NT and Sh5 cells upon combined HRG and E2 stimulation with concomitant 4-OHT treatment (Figure 4D and 4F). This suggests that, in contrast to PY537-ER $\alpha$, the effect of 4-OHT on PS118-ER $\alpha$ is independent of Memo. 4-OHT treatment did not give any significant difference in PY418Src phosphorylation compared to 4-OHT untreated cells (Figure 4D and 4G). However, PY418-Src was significantly higher in Sh5 cells upon combined 4-OHT and HRG treatment compared to similarly treated NT cells (Figure 4G, blue bars). These phosphorylation patterns were also observed using T47D Sh1 cells with less effective Memo knockdown (Supplementary Figure 5A$5 \mathrm{E})$. Our data suggest that ligand-activated ER $\alpha$ is needed for the effect of Memo on ER $\alpha$ sub-cellular localization and phosphorylation.

\section{Memo mediates migratory and proliferation effects downstream of HRG and E2}

Finally, we analyzed the effect of Memo on migration and proliferation downstream of HRG and E2. As described before $[9,10]$, we could observe Memodependent cell migration upon 24h HRG treatment (Figure $5 \mathrm{~A})$. Treating the cells with E2 induced cell migration in both NT and Sh 5 cells. Interestingly, combined HRG and E2 treatment did not induce cell migration in NT cells but did so in Sh5 cells, which migrated similarly to when stimulated by E2 alone. Treating the cells with 4-OHT decreased migration in all cases with the exception of NT cells treated with combined $\mathrm{HRG}+\mathrm{E} 2$, where migration was induced to similar levels as seen for HRG treatment (Figure 5A). Similar effects on migration were observed using T47D Sh1 cells that have a less effective Memo KD (Supplementary Figure 6A).

It was previously reported that Memo is required for E2-dependent and independent MCF-7 cell growth [13]. In our T47D model we could see an increase in proliferation with HRG and E2 treatments, however, this increase was similar between the NT and Sh5 cells (Figure 5B). In contrast, combined HRG and E2 treatment increased proliferation of NT cells compared to Sh5 cells (Figure 5B). Treating the cells with 4-OHT totally abolished the E2-mediated proliferation and slightly reduced the HRG-mediated proliferation in both NT and Sh5 cells (Figure 5B). Similar effects on proliferation were observed using the less effective Memo knockdown T47D Sh1 cells (Supplementary Figure 6B). Furthermore, the increase in proliferation of NT cells upon combined HRG+E2 treatment could not be observed in NT cells overexpressing the ER $\alpha-Y 537 \mathrm{~F}$ mutant, but instead

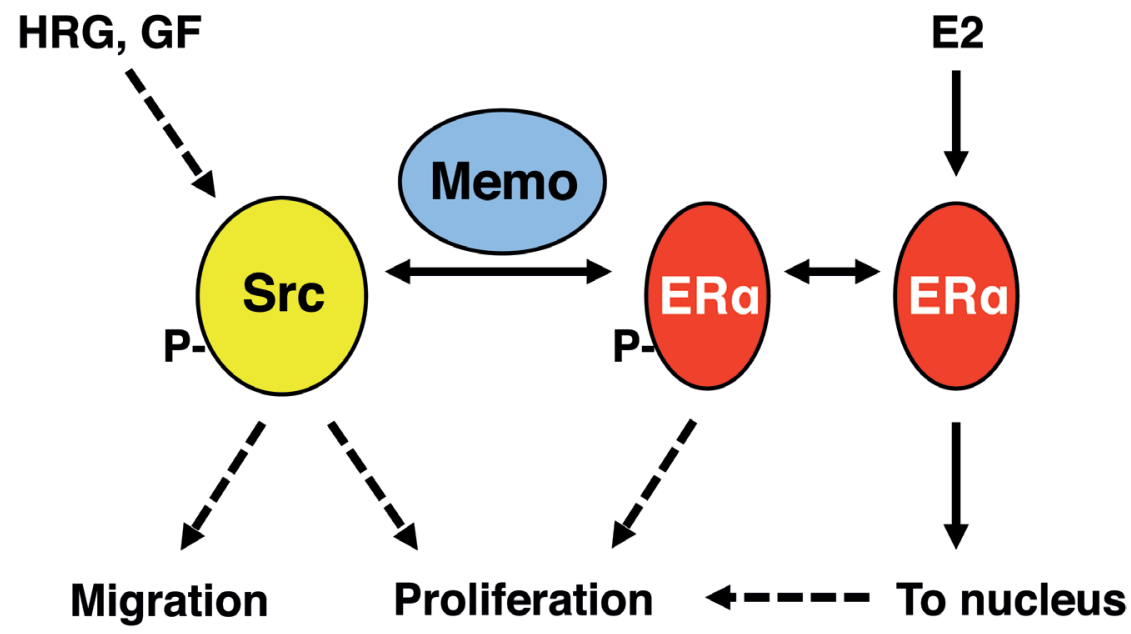

Figure 6: Summary model. Src is activated by various growth factor (GF) receptors, but also by E2 stimulation, at least in the presence of GFs. Memo interacts with Src and ER $\alpha$ to promote their binding upon HRG and E2 stimulation. This in turn increases Y418-Src and Y537-ER $\alpha$ phosphorylation as well as the extra-nuclear retention of ER $\alpha$. Memo is thus a crucial component at the intersection between E2 and HRG (and possibly other GF) signaling, and can thus promote their downstream effect on cell migration and proliferation. 
proliferation of these cells was comparable to Sh5 cells (Supplemental Figure 6C), suggesting that the ER $\alpha$-Y537 phosphorylation is essential for the Memo-dependent proliferation downstream of combined HRG and E2 stimulation.

To elucidate the dependence of ER $\alpha$ on Memomediated proliferation, we used the HER2+/ER $\alpha$ - breast cancer cell line SKBR3 treated with E2 and/or HRG. Here we could not observe any difference in proliferation with or without Memo (LZ control versus Sh5 Memo KD) and with or without E2 and HRG treatment combinations (Figure 5C). Interestingly, in contrast to T47D cells, the SKBR3 cells did not show any obvious reduction in PY418-Src upon combined HRG and E2 treatment (Figure $5 \mathrm{D}$ versus Figure 2D and $2 \mathrm{E}$ ). These results suggest that Memo together with a ligand-activated $\operatorname{ER} \alpha$ is needed for the combined effect of HRG and E2 on cell migration and proliferation, and that this is possibly mediated by Src phosphorylation and activation.

In summary, we show that Memo controls cell migration and promotes proliferation downstream of simultaneous HRG and E2 stimuli, and that this is likely mediated by a regulatory role of Memo in the ER $\alpha$-Src interaction, their phosphorylation and their function.

\section{DISCUSSION}

Endocrine therapy resistance resulting in metastatic recurrence contributes to death of many breast cancer patients. Memo plays an essential role in breast cancer metastasis [9] and in this study we show that Memo has a novel role at the hub between E2 and growth factor signaling, mediating crosstalk between these pathways. Our data suggest that Memo determines the localization, phosphorylation, and thus the function of ER $\alpha$ downstream of the HER2 receptor, and that this is achieved through a Memo-dependent interaction of ER $\alpha$ with Src. We show that Memo has a regulatory role on cell migration and proliferation downstream of a combined HRG and E2 stimulus in the ER $\alpha$ and HER2-positive breast cancer cell line T47D, and that this has consequences for tamoxifen treatment.

It is known that ER $\alpha$ interacts with Src and that this affects phosphorylation and activation of both [3-6]. Here we show that this interaction is dependent on a single protein, Memo, making it an important player in the crossregulation of the HRG and E2 pathways in breast cancer.

About $30 \%$ of breast cancer patients express $\mathrm{HRG}$, often in the absence of the ERBB2 amplicon [16, 17] of which many are both HER2 and ER $\alpha$-positive (e.g. Luminal B subtype). Memo was found to be expressed in $>40 \%$ of a cohort of primary breast tumors [9] and was localized to both the cytoplasm and the nucleus. Interestingly, its extra-nuclear localization correlated with aggressive molecular disease parameters (such as high grade, ER $\alpha /$ PR-negative, HER2-positive), as well as triple-negativity and Luminal B subtypes. Inversely, high nuclear Memo was associated with good prognostic factors, such as low grade and $\mathrm{ER} \alpha / \mathrm{PR}$ positivity [9]. In the context of HER 2 and ER $\alpha$-positive breast cancer, our data show that both Memo and ER $\alpha$ can rapidly colocalize to the nucleus upon HRG or E2 stimulation. The nuclear function of Memo here is still unknown. In contrast, upon simultaneous HRG and E2 stimulus both Memo and ER $\alpha$ are mainly localized extra-nuclear, thus preventing $E R \alpha$ transcriptional activity. Antagonizing effects of HRG on E2 signaling have previously been described [18-21]. Here we show that this can be mediated by Memo, which is able to increase the ER $\alpha-\mathrm{Src}$ interaction, resulting in elevated PY537-ER $\alpha$ and PY418Src, and a complex unable to enter the nucleus. In fact, these phosphorylations are needed for a tight interaction between extra-nuclear ER $\alpha$-Src $[5,7]$. This may lead to the lower ER $\alpha$ transcriptional activity (Figures 1B-1F), but increased proliferation (Figure 6B) that we observed following $\mathrm{HRG}+\mathrm{E} 2$ addition to cells. Although it is possible that increased Src activation contributes to this finding, the exact mechanism governing the rapid ER $\alpha$ extra-nuclear localization upon HRG and E2 treatment, as well as the potential for other factors to contribute to the $\mathrm{ER} \alpha$-Src interaction, is not fully understood. Efforts here could lead to better understanding and new treatment of breast cancer, in particular since this state would mimic the situation of premenopausal patients where circulating E2 and growth factors are present. Our data suggest that these patients may have lower nuclear Memo (and ER $\alpha$ ) levels, which would correlate with aggressive disease parameters [9]. Interestingly, the increased proliferation upon combined HRG+E2 treatment in NT cells (Figure 6B) was inhibited by 4-OHT, resulting in proliferation similar to Sh5 cells. These results lead us to propose that Memo might be diagnostic and indicative of a better response to endocrine treatment. On the other hand, Memo may be responsible for increased cell migration and metastasis upon inhibiting ER $\alpha$ with 4-OHT. This is intriguing and deserves deeper characterization since such knowledge may be of importance in understanding how tumor cells escape the primary site and if 4-OHT may promote this effect in a Memo-dependent manner in ER $\alpha$ positive cells. Our data also suggest that $\operatorname{ER} \alpha$ and Memo may influence the activity of each other with ensuing effects on cell migration (Figure 5A).

Memo is a copper-dependent redox protein that can change the oxidation status and function of RhoA as well as the activity of NADPH-oxidases [9]. Although beyond the scope of this report, the function of Memo's redox activity in the context of $\mathrm{ER} \alpha$ signaling will be very interesting to explore in the future, especially since it may have the potential to be blocked by small molecule ligands. In this respect, future studies with xenograft models would be interesting. However, the lack of metastasizing ER+/HER2+ breast cancer models currently 
prevent such studies. In summary, we propose that Memo connects E2 and HRG signaling through its interactions with $\mathrm{ER} \alpha$ and Src. Thus, Memo functions as a molecular hub in relaying E2 and growth factor signaling towards proliferation and migratory outputs (Figure 6). This is of relevance since breast cancer is regulated by hormonal and/or growth factor cues. In addition, the frontline treatment with 4-OHT of ER+ breast cancer may have different consequences if Memo is overexpressed or not, or whether it is localized to the nucleus or cytoplasm. Our data may be of value in understanding and treating breast cancer.

\section{MATERIALS AND METHODS}

\section{Cells and culturing}

The human breast cancer cell lines T47D, MCF-7, and SKBR3 (all authenticated by vendor, ATCC, Wesel, Germany) were cultured in Dulbecco's modified Eagle's medium (DMEM) (containing $4.5 \mathrm{mg} / \mathrm{ml}$ glucose) supplemented with $10 \%$ Fetal calf serum, FCS (all from ThermoFisher Scientific, Stockholm, Sweden) in 5\% $\mathrm{CO} 2$ at $37^{\circ} \mathrm{C}$ in a humidified incubator. Prior to treatment with $10 \mathrm{nM}$ estradiol (E2), $2 \mathrm{nM}$ Heregulin-1 $\beta$ (HRG) (both from Sigma Aldrich, St Louis, MO, USA), $20 \mathrm{nM}$ 4-hydroxytamoxifen (4-OHT, Tocris, Bristol, UK), and/ or $500 \mathrm{nM} \mathrm{Src} \mathrm{inhibitor-1} \mathrm{(Sigma} \mathrm{Aldrich)} \mathrm{the} \mathrm{cells} \mathrm{were}$ starved for $48 \mathrm{~h}$ in phenol-free DMEM containing $0.5 \%$ Dextran-charcoal (DCC) treated FCS. The generation of stable NT, LZ, Sh5, Sh1, and pLHCX-Myc-Memo cell lines was described before [9]. All cell lines were confirmed to be mycoplasma free.

\section{Real-time qPCR analysis}

Total RNA was isolated from cells using QIAshredder and RNeasy Mini Kit (Qiagen, Hombrechtikon, Switaerland). cDNA synthesis and amplification was performed using the Superscript III first-strand synthesis kit according to manufacturer's instructions (ThermoFisher). Quantitative real-time PCR (qPCR) analysis was performed with the Fast SYBR Green Master Mix (ThermoFisher) and the ABI7500 realtime PCR (ThermoFisher). Data was normalized to $18 \mathrm{~S}$ rRNA. See Supplemental Table I for primer sequences.

\section{Western blot analysis and immunoprecipitation}

Total cell extracts were prepared by resuspending the harvested cells in RIPA lysis buffer $(50 \mathrm{mM}$ TrisHCl, $\mathrm{pH} 8.0,150 \mathrm{mM} \mathrm{NaCl}, 5 \mathrm{mM}$ EDTA, $0.5 \%(\mathrm{v} / \mathrm{v})$ Nonidet P-40, 0.5\% (v/v) Triton X-100, 0.1\% Sodium
Deoxycholate, $2 \mathrm{mM} \mathrm{Na} \mathrm{VO}_{4}, 1 \mathrm{mM}$ DTT, and $1 \mathrm{x}$ EDTA-free protease inhibitor cocktail (Roche, Basel, Switzerland)). The extracts were incubated $30 \mathrm{~min}$ on ice and then centrifuged at $10000 \mathrm{x} \mathrm{g}, 10 \mathrm{~min}$ at $+4^{\circ} \mathrm{C}$. Protein concentration was measured and $30 \mu \mathrm{g}$ was separated on a $4-12 \%$ SDS-PAGE gel. The proteins were then transferred to a PVDF membrane (Bio-Rad laboratories, Hercules, CA, USA) and blocked using StartingBlock T20 buffer (Thermo Fisher). The membrane was probed using the primary and secondary antibodies listed in Supplemental Table II, followed by signal detection using ECL Prime kit and light sensitive films (GE Healthcare, Uppsala, Sweden). Quantification was performed using the ImageJ software (NIH Software, Bethesda, MD, USA). For immunoprecipitations, $400 \mu \mathrm{g}$ cytoplasmic lysate was incubated over-night with $5 \mu \mathrm{g}$ of Src antibody (N-16, Sc-284, Santa Cruz, Dallas, TX, USA) coupled to Dynabeads Protein G magnetic beads (ThermoFisher), or with $40 \mu \mathrm{l}$ anti-c-Myc magnetic beads (ThermoFisher). $5 \mu \mathrm{g}$ of non-targeting rabbit IgG (sc-2763, Santa Cruz) was used a control where appropriate. The bound complex was eluted using $100 \mathrm{mM}$ Glycine $\mathrm{pH} 2.8$ or with $50 \mu \mathrm{g}$ purified c-Myc peptide (ThermoFisher), and resolved on SDS-PAGE and blotted as described above. Elution with the c-Myc peptide is a prerequisite in order to detect Src, which roughly has the same size as the IgG heavy chain (60 $\mathrm{kDa}$ and $55 \mathrm{kDa}$ respectively).

\section{Chromatin immunoprecipitation (ChIP)}

ChIP analysis of the Cyclin D1 promoter was performed using starved T47D cells (as described above) treated with $2 \mathrm{nM}$ HRG and/or $10 \mathrm{nM}$ E2 for $30 \mathrm{~min}$. 1 $\mu \mathrm{g}$ of ER $\alpha$ antibody (MC-20, Santa Cruz) or $1 \mu \mathrm{g}$ of nonspecific rabbit IgGs was used for the ChIP, following the protocol described in [22]. The cyclin D1 primers were described in [13]. Detection was performed using qPCR and $\mathrm{ER} \alpha$ binding to the promoter was calculated as fold enrichment over IgG.

\section{Luciferase reporter assay}

The luciferase reporter assay was performed as described before [23]. In brief, T47D cells were seeded into 24 -well plates $\left(1 \times 10^{5}\right.$ cells/well). The next day, pRL-TK and $3 \times$ ERE-luc vectors were transfected using JetPrime transfection reagent according to manufacturer's instructions (Polyplus Transfection, IllkirchGraffenstaden, France) using a total of $1 \mu \mathrm{g}$ plasmid DNA. 4h after transfection, the media was changed to stripped media containing $10 \mathrm{nM} \mathrm{E} 2$ and/or $2 \mathrm{nM}$ HRG. $48 \mathrm{~h}$ later the luciferase reporter assay was performed [23] and firefly luciferase activity was normalized to renilla luciferase activity. 


\section{Immunofluorescence microscopy}

The subcellular localization of ER $\alpha$ and Memo was performed by seeding $300 \mu \mathrm{l}$ of $3 \times 10^{4} \mathrm{~T} 47 \mathrm{D}$ or MCF7 cells $/ \mathrm{ml}$ in ibidi 8 well $\mu$-slides (Ibidi, Martinsried, Germany). The cells were starved and treated with $2 \mathrm{nM}$ HRG and/or $10 \mathrm{nM}$ E2 (as described above) for different time points before fixation with $4 \%$ formaldehyde. The cells were then permeabilized for 10 min with $0.1 \%$ Triton X-100 (Merck) and blocked with 10\% horse serum in PBS (ThermoFisher) for $30 \mathrm{~min}$. The cells were stained with $300 \mathrm{nM}$ 4',6-diamidino-2-phenylindole (DAPI) for $5 \mathrm{~min}$, washed with PBS and then stained for $2 \mathrm{~h}$ at room temperature for ER $\alpha$ and Memo using ER $\alpha$ antibody (MC20, Santa Cruz) and Memo antibody (ab156614, Abcam, Cambridge, UK) respectively, both at 1:50 dilution. After washing with PBS, the cells were incubated with secondary Alexa Fluor antibodies (ThermoFisher) (Supplemental Table II) for $1 \mathrm{~h}$ at room temperature. The cells were washed, mounted using the ibidi-mounting medium (Ibidi), and imaged using an OlympusIX71 microscope (Olympus, Center Valley, PA, USA) and NISElements BR 3.2 Software (Nikon, Tokyo, Japan). Cells overexpressing GFP-tagged proteins were treated the same but without antibody incubations. Quantification of relative percentage nuclear staining was performed using the ImageJ software (NIH Software) using the algorithm: (Integrated density of nuclear fluorescence - (area of interest $\mathrm{x}$ mean fluorescence of background)) / (Integrated density of total cell fluorescence - (area of interest x mean fluorescence of background)). The image acquisitions and quantifications were made in a double-blind procedure.

\section{Construction of ERo-Y537F plasmid and transfections}

pEGFP-ER $\alpha$-C1-GFP (ER $\alpha$-GFP, WT) was purchased from Addgene (Cambridge, MA, USA) and used as backbone to construct pEGFP-ER $\alpha-\mathrm{C} 1-$ GFP-Y537F (ER $\alpha-Y 537 F-G F P)$ using the GeneArt site-directed mutagenesis system (ThermoFisher) following manufacturers protocol. The primers used to introduce the Y537F mutation were 5'-GAA CGTGGTGCCCCTCTTTGACCTGCTGCTGGAGA-3' (forward) and 5'-TCTC CAGCAGCAGGTCAAAGAGGGGCACCACGTTC-3' (reverse). The vector was transformed into competent Top10 cells (ThermoFisher), amplified, purified, and sequenced. The pEGFP-ER $\alpha-C 1-G F P$ and pEGFPER $\alpha$-C1-GFP-Y537F plasmids were used to transfect T47D NT and Sh5 cells using Lipofectamin 3000 system (ThermoFisher) following manufacturers recommendations. Visualization of ER $\alpha$-GFP expressing cells was done 2 days after transfection using an OlympusIX71 microscope (Olympus).

\section{Migration and proliferation assays}

The cell migration was measured using $8 \mu \mathrm{m}$ pore polycarbonate membrane transwell chambers (BD Biosciences, Stockholm, Sweden) coated with $25 \mu \mathrm{g} / \mathrm{ml}$ rat tail collagen (Roche) as described before with some modifications [24]. Cells were starved in $0.5 \%$ DCCtreated FCS in phenol-free DMEM for $48 \mathrm{~h}$ and then seeded at 25000 cells/well each transwell chamber and let migrate towards vehicle (DMSO), $2 \mathrm{nM} \mathrm{HRG,} 10$ $\mathrm{nM}$ E2 for $24 \mathrm{~h}$ and/or $20 \mathrm{nM} 4-\mathrm{OHT}$. The non-migrated cells were scraped from the top membrane using a cotton swab and the migrated cells were fixed in $4 \%$ paraformaldehyde and stained in $0.1 \%$ crystal violet (Sigma Aldrich). The cells were imaged using an Axiovert S100 inverted microscope (Carl Zeiss, Oberkochen, Germany). The migrated cells were counted in five different fields in duplicate wells, in at least three independent experiments and expressed as the mean \pm S.E.M.

For proliferation assays, $25000 \mathrm{cells} / \mathrm{ml}$ were let to adhere to the culture plate for $4 \mathrm{~h}$ in plain medium and then starved in phenol-free DMEM supplemented with $1 \%$ DCC-treated FCS for five days in the presence of vehicle (DMSO), $2 \mathrm{nM} \mathrm{HRG}, 10 \mathrm{nM}$ E2 for $24 \mathrm{~h}$ and/or 20 nM 4-OHT. Viable cells were counted using Trypan blue exclusion in at least three independent experiments and expressed as the mean \pm S.E.M.

\section{Statistical analysis}

The data represent means \pm S.D. or \pm S.E.M. from three or more independent experiments. Sample sizes were selected on the basis of preliminary experiments to ensure adequate power. After confirming that the data were normally distributed based on Shapiro-Wilk's normality test (Prism v. 6.0, GraphPad Software, La Jolla, CA, USA), statistical significances were determined using an unpaired, two-tailed Student's t-test, assuming unequal variances in single comparisons. For multiple comparisons one-way ANOVA followed by the Tukey's post-hoc test (assuming equal variances) or Dunnett's post-hoc test (assuming unequal variances) was performed. Differences were considered significant if the $\mathrm{p}$-value was $\mathrm{p}<0.05$.

\section{ACKNOWLEDGMENTS}

We want to thank Annelies Wouters for excellent technical assistance and Dr. Joëlle Rüegg for critical evaluation of the manuscript.

\section{CONFLICTS OF INTEREST}

The authors declare no conflicts of interest. 


\section{GRANT SUPPORT}

N.E.H. was supported by grants from Susan G. Komen for the Cure (SAC110041), the Swiss National Science Foundation (SNF 310030-149751) and the Novartis Research Foundation. I.N. and J.A.G were supported by the Swedish Cancer Fund (CAN2013/377), and J.A.G by the Robert A. Welch Foundation.

\section{Author contribution}

A.F., G.M., I.L., and I.N. designed and performed the experiments. N.E.H. and J.Å.G. provided valuable reagents. A.F., N.E.H., and I.N., wrote the paper. I.N. conceived the project. All authors discussed the results.

\section{Editorial note}

This paper has been accepted based in part on peerreview conducted by another journal and the authors' response and revisions as well as expedited peer-review in Oncotarget.

\section{REFERENCES}

1. Jia M, Dahlman-Wright K, Gustafsson JA. Estrogen receptor alpha and beta in health and disease. Best practice \& research Clinical endocrinology \& metabolism. 2015; 29: 557-68.

2. Osborne CK, Schiff R. Mechanisms of endocrine resistance in breast cancer. Annual review of medicine. 2011; 62: 23347.

3. Arnold SF, Obourn JD, Jaffe H, Notides AC. Phosphorylation of the human estrogen receptor on tyrosine 537 in vivo and by src family tyrosine kinases in vitro. Molecular endocrinology. 1995; 9: 24-33.

4. Arnold SF, Vorojeikina DP, Notides AC. Phosphorylation of tyrosine 537 on the human estrogen receptor is required for binding to an estrogen response element. The Journal of biological chemistry. 1995; 270: 30205-12.

5. Migliaccio A, Castoria G, Di Domenico M, de Falco A, Bilancio A, Lombardi M, Barone MV, Ametrano D, Zannini MS, Abbondanza C, Auricchio F. Steroid-induced androgen receptor-oestradiol receptor beta-Src complex triggers prostate cancer cell proliferation. The EMBO journal. 2000; 19: 5406-17.

6. Migliaccio A, Pagano M, Auricchio F. Immediate and transient stimulation of protein tyrosine phosphorylation by estradiol in MCF-7 cells. Oncogene. 1993; 8: 2183-91.

7. Castoria G, Giovannelli P, Lombardi M, De Rosa C, Giraldi T, de Falco A, Barone MV, Abbondanza C, Migliaccio A, Auricchio F. Tyrosine phosphorylation of estradiol receptor by Src regulates its hormone-dependent nuclear export and cell cycle progression in breast cancer cells. Oncogene.
2012; 31: 4868-77.

8. Yang Z, Barnes CJ, Kumar R. Human epidermal growth factor receptor 2 status modulates subcellular localization of and interaction with estrogen receptor alpha in breast cancer cells. Clinical cancer research. 2004; 10: 3621-8.

9. MacDonald G, Nalvarte I, Smirnova T, Vecchi M, Aceto N, Dolemeyer A, Frei A, Lienhard S, Wyckoff J, Hess D, Seebacher J, Keusch JJ, Gut H, et al. Memo is a copperdependent redox protein with an essential role in migration and metastasis. Science signaling. 2014; 7: ra56.

10. Marone R, Hess D, Dankort D, Muller WJ, Hynes NE, Badache A. Memo mediates ErbB2-driven cell motility. Nature cell biology. 2004; 6: 515-22.

11. Schlatter ID, Meira M, Ueberschlag V, Hoepfner D, Movva $\mathrm{R}$, Hynes NE. MHO1, an evolutionarily conserved gene, is synthetic lethal with PLC1; Mholp has a role in invasive growth. PloS one. 2012; 7: e32501.

12. Sorokin AV, Chen J. MEMO1, a new IRS1-interacting protein, induces epithelial-mesenchymal transition in mammary epithelial cells. Oncogene. 2013; 32: 3130-8.

13. Jiang K, Yang Z, Cheng L, Wang S, Ning K, Zhou L, Lin J, Zhong H, Wang L, Li Y, Huang J, Zhang H, Ye Q. Mediator of ERBB2-driven cell motility (MEMO) promotes extranuclear estrogen receptor signaling involving the growth factor receptors IGF1R and ERBB2. The Journal of biological chemistry. 2013; 288: 24590-9.

14. Pietras RJ, Arboleda J, Reese DM, Wongvipat N, Pegram MD, Ramos L, Gorman CM, Parker MG, Sliwkowski MX, Slamon DJ. HER-2 tyrosine kinase pathway targets estrogen receptor and promotes hormone-independent growth in human breast cancer cells. Oncogene. 1995; 10: 2435-46.

15. Zaoui K, Honore S, Isnardon D, Braguer D, Badache A. Memo-RhoA-mDial signaling controls microtubules, the actin network, and adhesion site formation in migrating cells. The Journal of cell biology. 2008; 183: 401-8.

16. Slamon DJ, Clark GM, Wong SG, Levin WJ, Ullrich A, McGuire WL. Human breast cancer: correlation of relapse and survival with amplification of the HER-2/neu oncogene. Science. 1987; 235: 177-82.

17. Tsai MS, Shamon-Taylor LA, Mehmi I, Tang CK, Lupu R. Blockage of heregulin expression inhibits tumorigenicity and metastasis of breast cancer. Oncogene. 2003; 22: 761-8.

18. Grunt TW, Saceda M, Martin MB, Lupu R, Dittrich E, Krupitza G, Harant H, Huber H, Dittrich C. Bidirectional interactions between the estrogen receptor and the cerbB-2 signaling pathways: heregulin inhibits estrogenic effects in breast cancer cells. International journal of cancer. 1995; 63: 560-7.

19. Nicholson BP. Ongoing and planned trials of hormonal therapy and trastuzumab. Seminars in oncology. 2000; 27 : 33-7; discussion 92-100.

20. De Amicis F, Giordano F, Vivacqua A, Pellegrino M, Panno ML, Tramontano D, Fuqua SAW, Ando S. Resveratrol, 
through NF-Y/p53/Sin3/HDAC1 complex phosphorylation, inhibits estrogen receptor alpha gene expression via p38(MAPK)/CK2 signaling in human breast cancer cells. Faseb J. 2011; 25: 3695-707.

21. Hutcheson IR, Knowlden JM, Madden TA, Barrow D, Gee JM, Wakeling AE, Nicholson RI. Oestrogen receptormediated modulation of the EGFR/MAPK pathway in tamoxifen-resistant MCF-7 cells. Breast cancer research and treatment. 2003; 81: 81-93.

22. Nalvarte I, Tohonen V, Lindeberg M, Varshney M, Gustafsson JA, Inzunza J. Estrogen Receptor beta controls MMP-19 expression in mouse ovaries during ovulation. Reproduction. 2016; 151: 253-9.
23. Kitraki E, Nalvarte I, Alavian-Ghavanini A, Ruegg J. Developmental exposure to bisphenol A alters expression and DNA methylation of Fkbp5, an important regulator of the stress response. Molecular and cellular endocrinology. 2015; 417: 191-9.

24. Gattelli A, Nalvarte I, Boulay A, Roloff TC, Schreiber M, Carragher N, Macleod KK, Schlederer M, Lienhard S, Kenner L, Torres-Arzayus MI, Hynes NE. Ret inhibition decreases growth and metastatic potential of estrogen receptor positive breast cancer cells. EMBO molecular medicine. 2013; 5: 1335-50. 